Василий Сенкевич

ORCID: 0000-0002-6694-2530

Естетственно-гуманитарный университет в г. Седльце

\title{
АНТИТЕЗА СЛОВА И РЕЧИ (НА ПРИМЕРЕ НАГОРНОЙ ПРОПОВЕДИ)
}

https://doi.org/10.34739/clit.2020.14.15

\section{ANTITHESIS OF WORD AND SPEECH (BY THE EXAMPLE OF THE SERMON ON THE MOUNT)}

The article covers the antithesis of positive and negative knowledge and its projection on the field of language. By the example of the Sermon on the Mount, the thesis of non-discursive nature of word and its contrasting to speech is affirmed. In connection with the antithesis under consideration, such questions of phenomenology are addressed as embodiment of meaning in a word, essential irrelevance of existing institutions and instances of the language. Distinction is made between authentic appeal and institutional methods of identification presented in nominal discourse.

Keywords: confession, sermon, word, discourse, cognition, sense

В противопоставлении тезиса антитезису обыденный рассудок (ratio) из соображений удобства выбирает тезис, чтобы потом его аргументировать. Такой выбор является понятным и объясняется склонностью любого здравомыслящего человека к пониманию, утверждению и приведению знания к непротиворечивой системе, сохраняющей свою устойчивость. Однако мыслящему и пытливому человеку необходимо хотя бы в рефлексии, отказываясь от предвзятости, удерживать в мышлении равновесие тезиса и антитезиса. «Субъект, поднявшийся до критики оснований собственной мысли и практики, обретает личностную уникальность,

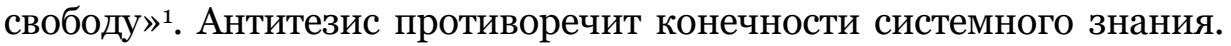
Система противополагает себя Богу, познание которого антиномично (антисистемно) и, по сути, и не допускает позитивного знания. Уму

\footnotetext{
${ }^{1}$ И. Кант, Критика чистого разума, [в того же:] Сочинения в 6 m., Москва 1964, т. 3, c. 100.
} 
непостижимый Бог познается через антитезис. Мы не можем знать, что он такое, однако ничто не мешает нам знать то, чем он не является.

Ортодоксальное позитивное языкознание «топчется» на позитивном тезисе, не решаясь перейти к негативному (непроявленному) антитезису. Пожалуй, единственной ценностью в системе позитивистского знания является прагматика языка. Однако в направленности оценочного позитивизма на «дело» забывается о том, что не имеет цены, - о Слове. Противопоставление «слова» и «дела» есть антитеза вечного «хода» и конечного результата, видимого явления и сокрытого феномена (сущности). В свете названной антитезы выразительно понимается, что такое проповедь, и приближается сущность исповеди.

Начнем с антитезиса. Проповедь не то, что Слово. Kazanie na górze (Нагорная проповедь)... Почему именно проповедь (kazanie)? Ведь известно, что проповедь - это произносимая речь. А в Нагорной проповеди говорит Слово (перифраза Христа). В отличие от речи, слово не сказывает, но само говорит. Называть Слово проповедью значит на место Логоса (слова) ставить дискурс (речь). А они не смешиваются, как не смешивается масло с водой, или начало с концом. Одно дело произносить речь, и совсем другое - говорить Слово.

Проповедь - речь религиозного содержания. Цель ее сообщать и разъяснять догматы веры. Это не что иное, как церковная пропаганда. Как существует политическая пропаганда (речь депутата), экономическая пропаганда (реклама), так существует и гомилетическая пропаганда (проповедь). Пропагандировать значит учреждать и конструировать институциональную действительность. В деле институционализации в мире на сегодняшний день преуспели два института - институт государства и институт церкви.

На поверку оказывается, что ни один из существенных признаков проповеди не характерен для Слова. Речь бывает истинной или лживой, словами же говорят Правду или обманывают. В слове, в сущности, не должно быть никакой риторики. Оно противится всякому пафосу. Слово - общепризнанный феномен искусства (искусство слова), речь же является фактом культуры (культура речи). В слове обнаруживается цивилизованность (изысканные слова) и варварство (грубые слова). Слово не является жанром речи; это вид вербального искусства - Слово о полку Игореве. Известны «Слова» и проповеди Кирилла Туровского. Митрополит Илларион 
говорит (а не произносит!) Слово о законе и благодати, ср. также: Слово, говоренное на Пасху.... Слова Григория Богослова и т.д.

Слово - область смыслов и уверенностей человека, его стойкости, а не устойчивости ${ }^{2}$. Однако уверовать во что-то не значит верить в него. «...Вера происходит от слышания, а слышание от проповедования...»3. Слово не слышат, но слушают. Правило «Слушать для того, чтобы слышать» 4 явно спекулятивное. Слышат сказанное: «Ты сказал» - «Я услышал». «Я тебя услышал!» (популярные кинофразы), однако: «Ты слушать исповедь мою сюда пришел, благодарю...» (Лермонтов, Мцыри). Между говорящими не происходит дискурсивный диалог - разговор, но осуществляется беседа (бел. гаворка). Говорящие - два человека, слушающие друг друга. Не подчиняясь один одному, они попеременно находятся друг у друга в послушании. Другое название для беседы - словесный дуэт.

В дискурсе, как и во всякой проповеди, господствует пафос личного позиционирования («Я», «Мы») и проявляется институт веры: «Вор должен сидеть в тюрьме... Я сказал» (Из фильма Место встречи изменить нельзя). «Мы вам покажем кузькину мать!» (Н. Хрущев). «Мы верим твердо в героев спорта...» (Из песни). Слово не имеет отношения к вере. Ему нет веры. Наивно верить на слово или верить чьим-то словам. Верят делу: «Ибо, (...) вера без дел мертва» (Иак 2:26). С утилитарно-прагматической точки зрения, слова ничего не стоят: «Брось, Люба, брось. Это слова. Слова ничего не стоят (...) Только ты меньше людей слушай. Слушай, но слова пропускай, а то ты доверчивая очень» (В. Шукшин, Калина красная). Парадоксально, однако стоимость подлинного слова в его незначимости и бесценности. Оно - бесценный дар (талант) человека.

Вера предполагает существование того или иного института, имеющего в языке номинативное представление. Одно дело верить в <Имярек>: в Бога, в партию, в народ, в светлое будущее и т.д., и совсем другое - уверовать во что-то. Однако ни в чем нельзя быть уверенным, кроме того, что есть. Оно очевидное и не порождает сомнения: «...to wieczne JEST, co ani było, ani będzie, ani może być, niepodległe wolnym wyborom, nieodstępne od najlepszości, nieludzko koniecznie»5. О нем ничего не скажешь. Все сказанное искажает его сущность, превращает в мертвую схему, понятие, образ. «Казом» реалия перебрасывается в актуальную область явления и прекращает

2 В. Кожевников, Нагорная проповедь - перифраз сточческой философии, https://filosofia.ru/7669o/, [дата доступа: 17.05.2020].

3 И. Златоуст, Беседы на Послание к Римлянам, Москва 2015, с. 729.

4 Митрополит Сурожский Антоний, Пастырство, Таганрог 2005, с. 109.

5 A. Bańkowski, Etymologiczny słownikjęzyka polskiego, t.1, Warszawa 2000, s. 3. 
свое бытие в качестве феномена. На смену предикативного есть приходит предметное «быть кем-чем». Происходит объективация и отчуждение его сущности

В познании и знании архиважно не смешивать сущность и существование (есть и существует). Парадоксально оказывается, что есть только то, чего не существует - «несуществующая сущность» (феномен). Для человека посвященного очевидно, что есть жизнь, а смерти нет. Смерть устанавливается врачом как факт. Однако не существует такого факта, как жизнь: живой - еще живой, но никогда: уже живой. У вещей и мыслей есть ход (ход вещей, ход мысли), а движения нет («Движенья нет», - сказал мудрец брадатый...» Пушкин, Движение); есть пора, но: «Времени нет самого по себе...» (Лукреций Кар, $O$ природе вещей); есть счастье, а доли (судьбы) нет и т.д. Есть смысл («Есть ли смысл?»). «А совесть есть у кого?» вопрос риторический. Для нас есть только то, в чем мы не сомневаемся.

Антитеза веры и уверенности - основная антитеза четырех Евангелий Нового завета. Уверение «А я говорю...» проходит через весь текст Нагорной проповеди:

Вы слышали, что сказано: «око за око и зуб за зуб». А я говорю вам: не противься злому (...) (Матвея 5, 38,39); Вы слышали, что сказано: «люби ближнего твоего и ненавидь врага твоего». А я говорю вам: любите врагов ваших, благословляйте проклинающих вас (...) (Матвея 5, 43); Вы слышали, что сказано древним: «не прелюбодействуй. А я говорю вам, что всякий, кто смотрит на женщину с вожделением, уже прелюбодействовал с нею в сердце своем (Матвея 5, 27, 28) 6 .

Фраза «Вы слышали, что сказано...» является обращением к прямой речи агентов, а рефреном звучащий элемент «Я говорю...» - само осуществляющееся Слово. Глагол говорить имманентен субъекту. Из того, что у человека есть дар слова, не следует, что кто-то ему его дал или подарил. Слово не является данным и не может служить основанием и аргументом в доказательстве. Как у соли есть дар солить, так у человека есть дар говорить; соль соленая, а человек - говорящий (Homo loquentes). Бессловесная тварь - животное. Но чтобы сказать, дара (таланта) не требуется. Речь по определению бездарна, что отнюдь не исключает ее мастерства и гениальности.

\footnotetext{
6 Здесь и далее цит. по: Библия Книги священного писания и нового завета.
} Канонические, Москва 2002. 
Искусство слова обнаруживается в его допредикативной несказанности: «Несказанное, синее, нежное...» (С. Есенин). Слово светит несказанным (неотраженным) светом. Говорящий парадоксально ничего не сказывает: «Мысль изреченная есть ложь. Взрывая, возмутишь ключи,- Питайся ими - и молчи» (Ф. Тютчев, Silentium!). Нельзя выразить и высказать мысль коммуникативной единицей, например, предложением. Она воплощается в тексте. Подлинное словесное искусство заключается в том, чтобы говорить, ничего не сказывая.

В словесном apm (искусстве) заняты артисты. В актах речи действуют акторы - отдельные лица, организации, институты. В слове важен звук - в нем воплощается смысл. Пропагандистские же лозунги, чтобы их услышали, должны гласить - быть громогласными: «Землю - крестьянам, заводы - рабочим». «Уберем урожай без потерь». «Хлеб - в закрома Родины». «Дадим стране угля» т.д. Слово не бывает ни громким, ни тихим. Его сила и целительный эффект в негласности (сокровенности). Голос выбор, история и культура. Слово - феномен доисторический (археологический). Негласность манифестируется шепотом: «Ты спрашивала шепотом: «А что потом? А что потом?» (Е. Евтушенко).

В дискурсе проявляется статусный мир в себе (бытие). В слове воплощается Другой мир - для нас. Эти параллельные миры не пересекаются.

Мир в себе ограничен системой господствующих правил и установлений. $\Phi$. Ницше называл государство самым холодным из чудовищ и говорил, что человек начинается только там, где кончается институт государственности7 7 . Ограниченные люди убоги - работники системы, чиновники, или «книжники» (по Христу). Этот мир без человека, а мысль о Богочеловеке ему кажется абсурдной. Этот мир можно понять до определенных границ, однако сущность его непознаваема. Познание есть вечное человеко- и богопознание.

Бог раскрывается как Человечность. Человечность и есть главное свойство Бога, совсем не всемогущество, не всеведение и пр. (...) Это человек, сам человек до ужаса бесчеловечен, искажает свой образ. Бог же человечен и требует человечности. Человечность есть образ Божий в человеке 8 .

Рационалисты хотят все понять, не видя при этом очевидного. Существует совершенно ложное отождествление рационального

7 Ibidem, c. 46-47.

${ }^{8}$ Н.А. Бердяев, Творчество и объективация, Минск 200о, с. 61. 
и понятного с очевидным, знакомым и близким. Наоборот. Очевидное, знакомое и близкое есть самое непонятное. Что может быть очевиднее света? Но свет есть самый непонятный феномен. Что может быть очевиднее для человека его самосознания (души)? Однако душа есть самое иррациональное и мистическое. 9 Что может быть очевиднее для человека слова? Но лингвисты до сих пор не знают, что оно такое. То, что уму непостижимо, находится за пределами понятного «этого» и определенного «такого». Оно познается недискурсивным (интуитивным) путем - искусством.

В отличие от проповеди, в слове нет ясности. Слово ничего не объясняет, и к нему не прибегают, чтобы что-то пояснить. Диалог «Вам ясно?» - «Да, нам все ясно?» не принадлежит к области словесности. Ясным бывает дело (ясное дело, понятное дело). Объяснить что-то не значит пролить на него свет - высветлить (ср.: ясное и светлое). Свет - состояние души: «Только мне не плачется на душе светло» (С. Есенин). «Я - свет миру. Кто со Мной - не блуждает во тьме: ему светит свет жизни» (Иоанна 8:12). Слово - свет и просвет в темном царстве. Нередко Его /просвет/ путают с зазором и химерой совести (ср.: зазрение совести).

Слово приближает мир для нас. Им не конструируется и не конституируется институциональная действительность, однако создается Другой («свой») мир. Он манифестируется приветливой улыбкой: «Улыбнулась всем: «Это я для вас», - А слеза катилась на улыбку» (Из песни). Мысль о близком расставании с миром своей повседневности драматически переживается человеком: «Не для меня придет весна (...) Там дева, с черными бровями, - она растет не для меня» (Из старинной казацкой песни). «Для вас поет Алла Пугачева» - и присутствующие в зале встречаются с совершенно другим миром. Реальность своего мира не происходит, но проходит, не поглощает, но целиком захватывает. Ничего не делая, все слушают звучащее Слово. Дело же всегда «кому»: «Что кому за дело, что кума с кумом сидела? Кому я сказал! Я кому сказал!» Сказывают <Имярек> - Ивану, Петру и т.д. Говорят для кого. И говорящий, и его адресат другие люди (друзья), совместно беседующие друг с другом. В подобном другом диалоге нет персональной ответственности, однако каждый отвечает за свои слова («за базар»).

В векторе «для кого» присутствует градационная инициация (посвящение) - путь восхождения по ступеням совершенства. Поющий на сцене артист посвящает в свой талант находящихся в зале

\footnotetext{
9 Б.П. Вышеславцев, Этика преображенного эроса, Москва, 1994, с. 132.
} 
зрителей, облагораживая и преображая их. Слово как таковое не может не быть посвящением. Подобное посвящение для человека есть Благо. Удивительно, что ослепленный и больной отраженным светом современный мир не всегда в состоянии принять его благодати. Мешает ему в том ratio (рассудок). «Это болезнь рационализм, которого в редком нет сердце у научников, хотя в слове он не открывается» ${ }^{10}$. Аналитический ум выбирает систему. Пример системы - маятник, в котором подвешенный шарик механически движется (мается). Такая «подвешенность» считается настоящей жизнью людьми, которые ее знают, однако не посвящены в Ее сущность. Воплощающая логос жизнь не заслуживает нарекания («Такая жизнь»).

C неимоверной силой Благо и талант благодати воплощен в Боге. Убогость - их отсутствие: бел. нябога, нябожчык, небажаты. Только благодатное слово есть слово подлинное. Все остальные пошлые, хотя и доброжелательные. Благодать отсутствует в исторически закрепившихся пошло-искренних формулах вежливости: «Добрый день», «Доброй ночи». «Здравствуйте», «Спасибо» и т.д.; «Что надо дяде сказать?» - «Спасибо». «Что пожелать на ночь? - «Спокойной ночи». Звучит парадоксально, однако в этикетном «Спасибо» (Спаси <тебя> Бог) нет ни капли божественного начала. Вряд ли в момент произнесения этой формулы традиционной культуры кто-нибудь думает о Боге. Такие скудные на благодать слова - «не те».

Слово не спасает человека от маеты этого мира, однако исцеляет его, избавляя от патологий движения и покоя. Патология отсутствует в альтернативном динамизму холистическом (др.-греч. ӧ $\lambda о \varsigma$ «целый») статичном состоянии. Его названия: бел. неруш, рус. безмолвие, невозмутимость, неизменность, девство, целомудрие. В нем воплощен феномен поэзии. Высшая Ее ступень есть совершенное безмолвие - «ни, ни». Тишина тревожная и пафосная. Другое название описываемого состояния - Царствие небесное. К нему - пределу осуществления своей аутентичности (самости) устремленно в своем поведении все живое. Оно находится за пределами смерти, а не после нее. Смерть также не после жизни. Мертвое - все, что уже было - патологически вплетено в повседневность. Становясь обычным, оно культивируемым обычаем. Лакмусовой бумажкой всяческой проявленной в жизни мертвечины является скука (ср.: смертельная скука).

1о Мысли Святителя Феофана Затворника о сокровенном мире человека, Минск 2014, c. 55 . 
В градуированной эволюции слова отсутствует пафос подъема. Слово не будит к активной деятельности и само не является деятельностью (процессом). Ни одна из дорог, которые мы выбираем, не ведет к Благу. Найденный Путь к нему - не подъем, а восхождение к своему пределу через познания своей альтернативы - Другого. Однако взойти на вершину - не значит подняться на гору. Восхождение есть подвиг, а подъем - это неоправданный героизм. В героизме, как и во всяком «изме», нет героического начала и подвижничества. Подвиг - не жертва во имя идеи, но путь к Другому, ради своего совершенства. Здесь аскетическое усилие и возвышающая аскеза, ср.: результаты, но: подвижки. Гора - это «круто», однако: «Укатали сивку крутые горки» (Посл.). Вершина «стремная»: укр. стрімка; бел. строма; строма - край, вертикаль; польск. stromy; жарг.: стремно, стрематься.

Слово не поднимет человека вверх. Благодаря ему он устремляется ввысь - возвышается, получая превосходство над тварным миром. Другое название для устремленности интенциональность. Восходящему некуда падать, однако он «стремается» и рискует сорваться. Сорваться для говорящего - это не удержаться и потерять выдержку; говорить опрометчиво, наговорить лишнего, обрушиться на кого-то бранью и, в результате, все испортить. Просчитать все риски невозможно. Для этого есть страховка - авторитетное и испытанное Слово Другого. Апеллируя к нему, говорящий вопрошает: Dobrze mówię? Правда? Не правда ли? Правда, мама? Ему не говорят «Спасибо!», однако благодарят «ненужными» вещами - аплодисментами, цветами, словами восхищения.

Поддержка Другого не есть «подвязка» (и не подвизание). Здесь не идет речь о согласии («да» или «нет»). Согласие и согласование - системные моменты («Любви моей не опошляй согласьем» В. Вишневский). Слово «да» заменяется словами «Правда», «Лады» (разг.) и т.п. Говорящий не ждет одобрения, однако живо отзывается на похвалу и оказанные почести. Слово не награда, но uczta (uczczenie). Оно учтивое и честное (слово чести), однако в нем нет ни грамма утилитарной годности и институционального достоинства.

В отличие от проповеди, словом не сообщаются факты, не разъясняются теоретические положения и не объясняются понятия. Миссия Слово - вещать благо, не злословя и не звуча зловеще. Слово вещее. Однако весть не новость (ср.: вести с полей, но: новости из регионов). Вещания нет в устной или письменной передаче сообщении. Смоделируем ситуацию. 
Один бизнесмен (пусть это будет крутой русский) приехал в женский монастырь, зашел в монастырскую лавку. Видит, все пишут и подают записки - кто за здравие, кто за упокой. «Что за дела?»думает себе. - «Совают самому Богу какие-то записочки». А возьмука я и обращусь к нему с письмом. Так-мол и так, Боже... Изложу факты, поделюсь благими намерениями и планами на будущее.

А тут зашла с обходом в лавку настоятельница. Так и так, матушка, говорит, имею к Богу дело и хочу написать ему письмо. На что матушка отвечает: «И, голубчик, не дойдет, до Бога твое письмо. Не Богово это - читать, но кесарево. Да и написать ты собрался ему, видимо, невесть что. Вестимо ли дело, делится с Богом своими планами? Пропадет твое письмо без вести Бог весть где. Пошлите Всевышнему весточку.

Письмо как письменное сообщение является обращенной речью - дискурсом. Ср. традиционный зачин: «Во первых строках своего письма сообщаю, что...». В письме актуализируется - первое (первые новости, из первых уст), а в вестях, наоборот, последнее (последние известия). Вести шлют и посылают. Посыл - интенция говорящего: Привет - благословие, Пошел ты... - злословие. В вести не содержится обращения и клича, однако присутствует апеллящия (ср. пол. apel „wezwanie, odezwa; odwołanie się do kogoś”).11

Каждый отмечает то, что для него важно. Итогом подобного нотирования выступает текст. Говорят текстами. В слове текст обнаруживается рефлекс, аналогичный тому, что и в слове притча. Все же остальное, что, например, чиновники или студенты пишут вслед за начальником или преподавателем, - дискурс. Письмо является эпистолярным жанром речи.

Рефлексивную апеллятивность замечаем в Привет $u$ его ответной аналогии - Привет (Каков привет - таков и ответ). А вот «Здравствуйте!» - «Здравствуйте!» - это уже трансакция (Ср.: «Как аукнется, так и откликнется»). В слове живет душа. Отзываются душой, но откликаются сердцем: сказать что-нибудь можно «в сердцах». Дела сердечные для души не характерны. Душа инстанция, природа же сердца институциональная (открыть сердце, но: распахнуть душу).

Не секрет, однако, что не всякое слово апеллятивное. Многие слова говорятся безапелляционно - с апломбом, самоуверенно, декларативно, напр.: «Все мы, бабы, стервы...» (Из песни); «Заявление хочу сделать». - «По какому вопросу». - «По насущному. Все менты - козлы» (из фильма Ментовские войны). Примером

\footnotetext{
${ }^{11}$ Popularny stownikjęzyka polskiego, opr. E. Sobol, Warszawa 2002, s.19.
} 
безапелляционности могут служить слова Собакевича в поэме Н.В. Гоголя Мертвые души.

/Чичиков:/- Конечно, всякий человек не без слабостей, но зато губернатор какой превосходный человек

- Губернатор превосходный человек?

- Да, не правда ли?

- Первый разбойник в мире! (...)

И лицо разбойничье! - сказал Собакевич. (...) Он да еще вицегубернатор. Это Гога и Магога.

(...) все христопродавцы. Один там только и есть порядочный человек: прокурор; да и тот, если сказать правду, свинья.

К авторитету Другого апеллируют словно в вышестоящую инстанцию. С Ним нет отношения зависимости и подчинения, однако каждый «под Ним ходит». А все ходят под Всевышним Другим Богом. Он - не тяжкий крест, который принуждают нести во имя иллюзорного будущего, которое никогда не наступает, но благое иго. «Ибо иго Мое благо...» (Матвея 11:30). К Другому взывают, ища оправдания своим словам и поступкам. Человек отчитывается по должности, однако оправдывается за свое звание. Высшее звание на земле и великая загадка, перед которой бессилен рассудок - Человек. Парадоксально, однако чтобы оправдать его, нет необходимости в соответствии занимаемой должности. Оправдание - область правды, а не права. Оправданием не снимается вина, однако устраняются погрешности поведения. Нет оправданного действия есть оправданный или неоправданный поступок. Правда у каждого своя, однако, как свидетельствует история, много есть охотников ее приватизировать - сделать «одной» и «чьей».

Таким образом, принцип антиномичности языка подвигает на пересмотр традиционной точки зрения на «Нагорную проповедь» и укоренившиеся представления о проповеди как жанре гомилетики. Если называть вещи своими именами, то «Нагорная проповедь» никакая не проповедь, а Слово, обладающее всеми логистическими характеристиками.

\section{Литература}

Bańkowski A., Etymologiczny stownikjęzyka polskiego, T. 1, Warszawa 2000. Библия Книги священного писания и нового завета. Канонические, Москва 2002.

Popularny stownik języka polskiego, opr. E. Sobol, Warszawa 2002.

Бердяев Н.А., Творчество и объективация, Минск 2000.

Иоанн Златоуст, Беседы на Послание к Римлянам, Москва 2015. 
Кант И., Критика чистого разума, [в:] Кант И. Сочинения в 6 т., Т. 3, Москва 1964.

Кожевников В., Нагорная проповедь - перифраз сточческой философuи? https://filosofia.ru/7669o/, [дата доступа: 17.05.2020].

Митрополит Сурожский Антоний, Пастырство, Таганрог 2005.

Мысли Святителя Феофана Затворника о сокровенном мире человека, Минск 2014.

Щедровицкий Д., Слушая Нагорную проповедъ, Москва 2016.

\section{References}

Bańkowski A., Etymologiczny stownikjęzyka polskiego, T. 1, Warszawa 2000. Bibliâ Knigi svâ̂sennogo pisaniâ $i$ novogo zaveta. Kanoničeskie, Moskva 2002.

Popularny stownik języka polskiego, opr. E. Sobol, Warszawa 2002.

Berdâev N.A., Tvorčestvo i ob"ektivaciâ, Minsk 2000.

Ioann Zlatoust, Besedy na Poslanie k Rimlânam, Moskva 2015.

Kant I., Kritika čistogo razuma, [v:] Kant I., Sočineniâ v 6 t., T. 3, Moskva 1964.

Koževnikov V., Nagornaâ propoved' - perifraz stoičeskoj filosofii? https://filosofia.ru/76690/, [data dostupa: 17.05.2020].

Mitropolit Surožskij Antonij, Pastyrstvo, Taganrog 2005.

Mysli Svâtitelâ feofana Zatvornika o sokrovennom mire čeloveka, Minsk 2014.

Ŝedrovickij D., Slušaâ Nagornuû propoved', Moskva 2016. 